\title{
Speed and Leakage Power Trade-off in Various SRAM Circuits
}

\author{
Neeraj Kr. Shukla, Shilpi Birla, R.K. Singh, Member IACSIT and Manisha Pattanaik
}

\begin{abstract}
The growing demand of multimedia rich applications in handled portable devices continuously driving the need for large and high speed embedded Static Random Access Memory (SRAM) to enhance the system performance. Many circuit techniques, e.g. body bias, bit charge recycling etc., have been proposed to expand design margins at low voltage operation while reducing leakage current at standby mode, but the performance is analyzed at the cost of speed and this issue is not addressed widely. Also due to continuous scaling of CMOS, the process variations also affect the performance of SRAMs. This paper presents the analysis of low leakage SRAM along with the speed factor.
\end{abstract}

Index Terms-Static Random Access Memory, Process Variation, Leakage Current, Low-Voltage Operation.

\section{INTRODUCTION}

The rising demand for multimedia rich applications in handheld devices drive the need for large and high speed portable devices continue to drive the need for large and high speed SRAM (Static Random Access Memory) to enhance the system performance. The power sensitive portable devices need to reduce the dynamic and standby power consumption in order to meet the battery life time. As the leakage power in the CPU is mainly dominated by the large on die SRAMs as the rest of the processor has been greatly optimized to reduce the power consumption. The low transistor leakage has traditionally been achieved by increasing the transistor threshold voltage $(\mathrm{Vt})$, gate length and gate dielectric thickness at the cost of speed and area. The low-power requirement has often been met by compromising the SRAM performance through the adoption of slower performing transistors with low leakage and lowering the supply voltage.

Lowering of Vdd in SRAM has been applied to reduce the standby leakage power and the active power associated with switching the highly capacitive bitlines and wordlines during active operations. However, the operating margin of SRAM cell sets the lower limit of operating voltage. To ensure adequate read/write margins of SRAM cells, the SRAM is required to run above a minimum supply voltage during the active mode and standby mode. However, device scaling of large SRAM has not kept pace with technology scaling due to the rising process variations in scaled SRAM cells, and the growing size of embedded SRAM [2]. Many circuit techniques have been proposed $[2,3,4]$ to expand design margins at low-voltage operation while reducing leakage current at standby mode. However, the performance cost from trading off transistor speed for lower leakage is not clearly addressed. This paper analyzes the low leakage

Manuscript received September 29, 2010 in SRAM cell along with the effect on speed.

In it, Section-II discussed the 6T-SRAM Cell and the analysis is discussed in the Section-III. It also discusses various SRAM Cell topologies. At Table-1, the performance review of the conventional SRAM Cells at various technologies is being compared.

\section{CONVENTIONAL 6T-SRAM CELL}

A typical SRAM, shown in Fig. 1, consists of several blocks, e.g., memory cell arrays, address decoder, column multiplexers, sense amplifiers, I/Os, and a control circuitry. The functionality and design of every component of an SRAM block can be found in [7]. A schematic of 6T SRAM cell is as shown in the Fig. 1. The bit value stored in the cell is preserved as long as the cell is connected to a supply voltage whose value is greater than the Data Retention Voltage (DRV). This is due to the presence of cross-coupled inverters in the 6T SRAM Cell. In an SRAM cell, the pulldown NMOS transistors and the pass-transistors reside in the read path. To achieve a high read stability, the pulldown transistors are made stronger than the pass-transistors. The pull-up PMOS transistors and the pass-transistors, on the other hand, are in the write path. Although using strong PMOS transistors improves the read stability, it degrades the write-margin. A proper sizing of pass-transistors is required to achieve an adequate write margin [5].

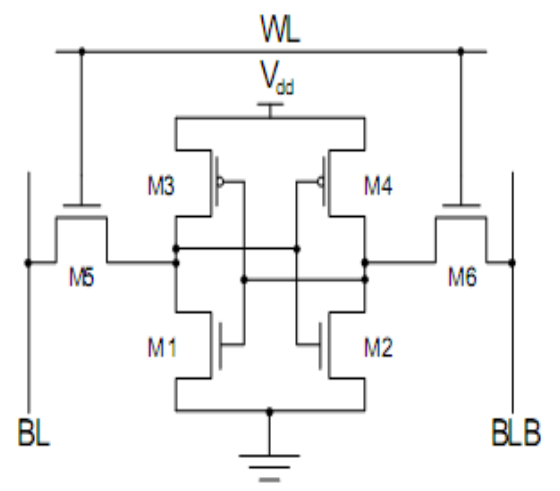

Fig 1. Conventional 6T SRAM Cell [7]

\section{ANALYSIS OF CONVENTIONAL 6T-SRAM CIRCUITS}

In this section we have analyzed the performance of various SRAM circuits with respect to speed and leakage power. Various methodologies have been used to improve the speed and leakage power consumption of the cell as discussed as below:

\section{A. Dynamic SRAM PMOS FBB (Forward Body Bias)}

An effective approach to help to reduce the leakage power involves dynamically changing the body bias of 
the transistors. This technique can be either applied at the full-chip level or a finer granularity. Typically, a block-level approach is preferred as it provides leakage power reduction whenever the functional block becomes idle, regardless of the operation of the rest of the chip.

In this approach, a control loop is required to provide appropriate substrate bias based on the operation state of the functional block. A block diagram of this approach is shown in Fig. 2. When the block enters the standby state, reverse body bias (RBB) is applied to increase the $\mathrm{Vt}$ of the transistors, and thus decreasing the sub-threshold leakage current. When the block returns to the active state, $\mathrm{RBB}$ is removed to decrease the $\mathrm{Vt}$ of the transistors, and thus restore the nominal performance of the transistors [7].

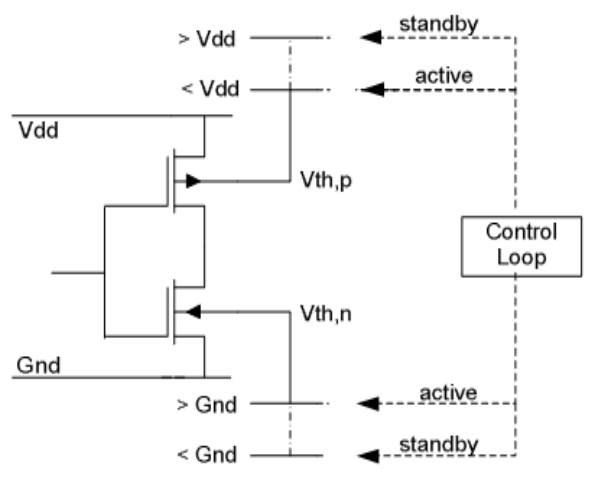

Fig.2. Dynamic Body Bias [7]

The key issue with this approach is that the range of threshold adjustment is limited, which in turn limits the amount of sub-threshold leakage reduction. However, the advantage of this approach over the sleep transistors is that it can be implemented without incurring any delay penalty. This can be done by applying forward body bias (FBB) when the block is in the active state. Under the FBB, the $\mathrm{Vt}$ of the devices is lowered, thus increasing the performance. As a tradeoff, FBB increases the subthreshold leakage. It is also crucial to limit FBB to ensure that the source-bulk pn-junction remains in cutoff when FBB is applied. Lowering the power supply is known to be one of the best methods in reducing the power consumption of integrated circuits. Low power operation can be achieved by lowering the operating voltage in active and/or inactive modes. Moreover, typically SRAM can retain the data at a lower voltage (Standby-VCCmin) than the minimum voltage needed for Read / Write (ActiveVCCmin).

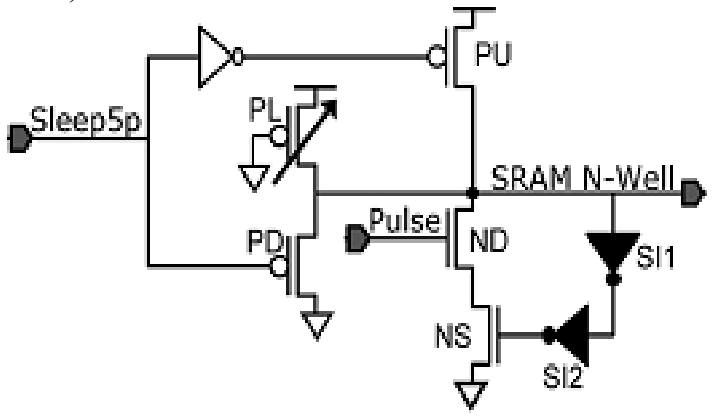

Fig.3. SRAM Circuit using Forward Body [8]
The PMOS strength in the 6T-SRAM cell is essential to maintain the cell stability during the active mode. This is particularly important for low-voltage operation. The process solution of using low-Vt PMOS is often prohibitive due to the excessive large transistor leakage, but the adaptive body-bias design is shown to be effective in transistor performance improvement without the cost of leakage-power [9]. The column-based SRAM PMOS bodybias has been proposed to improve both the Read and the Write VCCmin [10]. The design keeps the N-well forwardbiased in idle mode, which increases the leakage power, and charges it above Vcc for the selected column during write operation. In this design, a dynamic forward body bias for the PMOS in the SRAM cell is developed to improve the robustness of low-voltage operation while meeting stringent product power requirements at minimum design overhead. The sub-array based design is adopted to keep the area overhead minimal. It applies forward-bias to the activated sections of the array during both Read and Write operations. Although this will degrade the Write-Margin but the overall VCCmin distribution will be improved, since the VCCmin for large arrays are Read limited. The amount of FBB is determined by the ratio of two PMOS devices (PL and PD), which has a built-in programming control [9].

To meet fast and dynamic requirements, an NMOS pulldown path, formed by transistors ND and NS, and controlled by a pulse signal, is employed to achieve the fast voltage transition at the $\mathrm{N}$-well. A feedback or shut-off mechanism is also used to prevent the $\mathrm{N}$-well voltage from dropping too low and causing excessive junction leakage. The trip points of the inverters, SI1 and SI2, are optimized to meet this need as shown in Fig. 3. The pull-down signal pulse is programmable and generated off the wakeup signal (Sleep5p). It starts the discharge of the N-well voltage one cycle before the WL is turned on in order to ensure that the $\mathrm{N}$-well voltage level has reached intended static level. It is shown that the design has achieved high-frequency operation over a wide voltage range, a maximum frequency operation of $2.7 \mathrm{GHz}$ at as low as $0.9 \mathrm{~V}$, and $3.8 \mathrm{GHz}$ at 1.1 $\mathrm{V}$ [9]. This operating frequency in $45 \mathrm{~nm}$ technology represents a $25 \%$ improvement over previously reported results in $65 \mathrm{~nm}$ technology. The $256 \mathrm{~Kb}$ dual blocks operates at $2.3-4.2 \mathrm{GHz}$ and consumes $16-20 \mathrm{mw}$ total power using $0.7-1.2 \mathrm{~V}$ variable $\mathrm{V}_{\mathrm{CORE}}, 1.2 \mathrm{~V}$ fixed $\mathrm{V}_{\mathrm{LLC}}$ and standby of $0.9 \mathrm{~V}$ at $85^{\circ} \mathrm{C}$. Power reduction decreases at very high activity of one access every three cycles (33\%) activity Fig. 4.

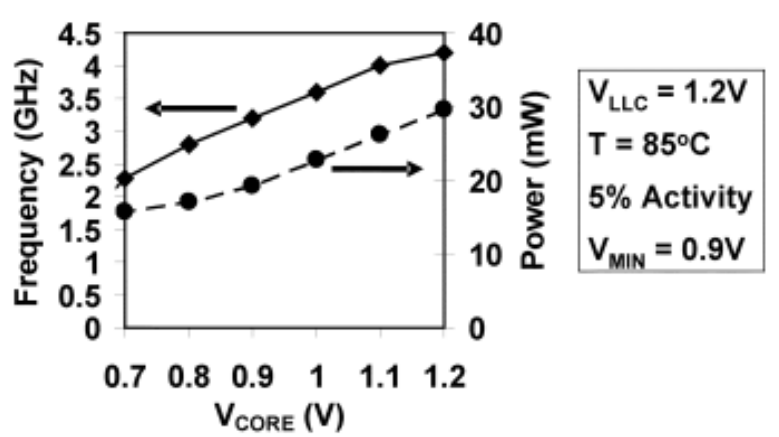

Fig.4. Chart showing voltage vs. frequency and power [14] 


\section{B. Bit-Line Charge Recycling}

The charge-recycling SRAM (CR-SRAM) reduces the read and write powers by recycling the charge in bit lines. When $\mathrm{N}$ bit lines recycle their charges, the swing voltage and power of bit lines are reduced to $1 / \mathrm{N}$ and $1 / \mathrm{N}^{2}$, respectively. The CR-SRAM utilizes hierarchical bit-line architecture to perform the charge-recycling without static noise margin degradation in memory cells. It can recycle the charge in bit lines during both read and write operations, where as the conventional charge-recycling SRAM recycles the charge only during write operations [21]. The proposed CR-SRAM not only reduces the read power by using the charge-recycling read operation, but also it does not have the power and delay overheads due to the read-to-write mode change of the conventional charge-recycling SRAM. With the hierarchical bit line, the CR-SRAM performs bitline charge-recycling without static noise margin degradation. Therefore, it can reduce both read and write powers with good reliability. In the simulation, the CRSRAM saves $17 \%$ read power and $84 \%$ write power compared with the conventional SRAM.

\section{C. $\quad$ Single-Ended 10T-SRAM Cell (10T-S SRAM)}

To improve the 8T-SRAM, a 10T non-recharge SRAM with a single-end read bit-line is being proposed [5]. Thereafter, we call "10T-S SRAM". Two PMOS transistors are appended to the 8T SRAM cell, which results in the combination of the $6 \mathrm{~T}$ conventional cell, an inverter and transmission gate. The additional signal (/RWL) is an inversion signal of a read word-line (RWL). It controls the additional PMOS transistor (P4) at the transmission gate. While the RWL and /RWL are asserted and the transmission gate is on, a stored node is connected to an RBL through the inverter. It is not necessary to prepare a precharge circuit because the inverter fully charges/discharges the RBL [12]. In all the SRAMs, the worst cell with the worst thresholdvoltage variation determines the delay. At a supply voltage of $1.0 \mathrm{~V}$ the $10 \mathrm{~T}-\mathrm{S}$ SRAM is faster than the $8 \mathrm{~T}$ SRAM because neither the precharge circuit nor the keeper circuit is needed in it.

\section{Ultra Low-Power SRAM}

An ULP SRAM with column redundancy, electrically programmable fuse, and PBIST (Programmable Built-inSelf-Test) has been built and packaged in an 8 metal Layer Land Grid Array (LGA) package with the flip-chip technology. The large SRAM size was intended to explore the limitation of process technology and variability of SRAM cell [20].

The standby leakage of $1 \mathrm{Mb}$ SRAM operating in the standby, low leakage-power and high-speed mode are as, in standby mode the SRAM macro draws $12 \mu \mathrm{A}$ of leakage at $\mathrm{Vdd}$ of $0.5 \mathrm{~V}$. The leakage current increases to $22 \mu \mathrm{A}$ for the low power operation of $\mathrm{Vdd}$ at $0.7 \mathrm{~V}$ and $90 \mu \mathrm{A}$ for the operation of $\mathrm{Vdd}$ at $1.2 \mathrm{~V}$.

The maximum access frequency of $1 \mathrm{Mb}$ SRAM is as shown in the Fig.5. The SRAM can operate over a wide range of supply voltages from $1.2 \mathrm{~V}$ down to $0.5 \mathrm{~V}$. It achieves $1.1 \mathrm{GHz}$ frequency at the nominal voltage of $1.2 \mathrm{~V}$ and $250 \mathrm{MHz}$ at $0.7 \mathrm{~V}$. This performance represents the highest reported access frequency for the same class of SRAM standby power consumption and SRAM size.

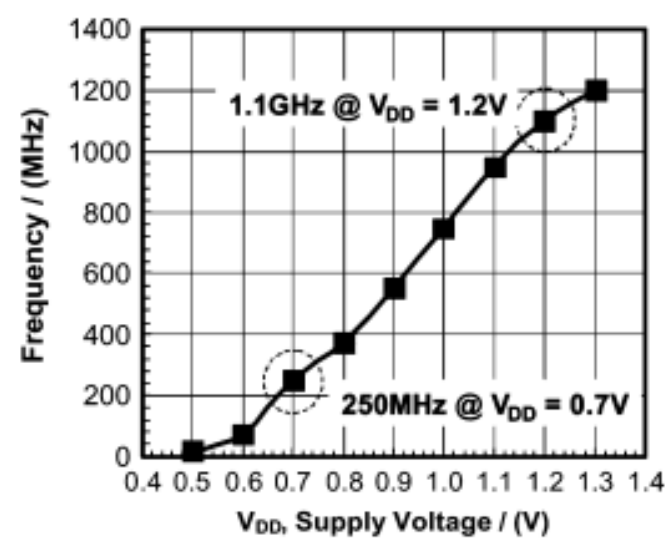

Fig.5. Supply Voltage vs. Frequency Curve [19]

\section{E. Sub-threshold 10T-SRAM Cell}

A $256 \mathrm{~kb} 65 \mathrm{~nm}$ bulk CMOS test chip uses the 10T bitcell and the architecture shown in Fig.5. The memory has eight $32 \mathrm{~kb}$ blocks with 256 rows and 128 columns each. A single 128bit Dual I/O (DIO) bus serves all eight blocks. In the initial instantiation of the sub-threshold memory, only one read or write can occur per cycle, however the $10 \mathrm{~T}$ bitcell would allow a read and write access to the same block in one cycle. Such a dual-port instantiation of the memory would require a second Dual $\mathrm{I} / \mathrm{O}$ bus and additional peripheral logic. A combined global wordline and block select signal assert a local wordline that triggers either WLRD or WLWR. For a write access for the accessed row turns off. The write drivers simply consist of inverters with transmission gates, which turn-off when the memory is not writing to minimize leakage on the write bitlines (BL and BLB). The power supply to the WL drivers is routed separately to allow a boosted WL voltage. This technique improves the access speed and increases the robustness to local variations. The read bitline (RBL) is precharged prior to read access, and its steady-state value is "sensed" using a simple inverter. Column and row redundancy is a ubiquitous technique in commercial memories used to improve yield. For this analysis of the SRAM, it is being assumed that the availability of one redundant row and column per block.

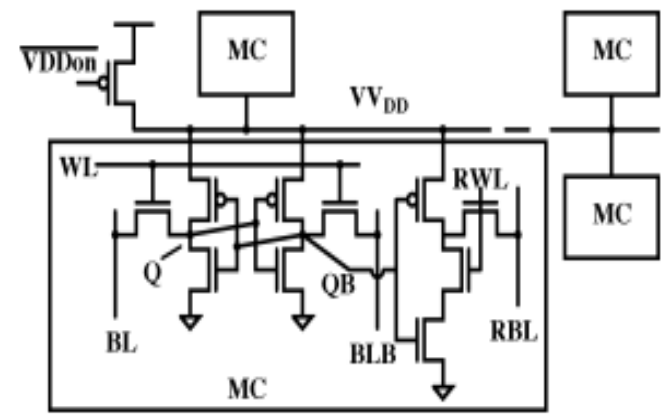

Fig.6. Sub-threshold 10T-SRAM Cell [14]

At $27^{\circ} \mathrm{C}$, the $10 \mathrm{~T}$ memory saves $2.5 \mathrm{X}$ and $3.8 \mathrm{X}$ in leakage power by scaling from $0.6 \mathrm{~V}$ to $0.4 \mathrm{~V}$ and $0.3 \mathrm{~V}$, respectively and over $60 \mathrm{X}$ when $\mathrm{Vdd}$ scales from $1.2 \mathrm{~V}$ to 
$0.3 \mathrm{~V}$. Scaling also gives the expected savings access, as shown in Fig.7, it shows the measured frequency of operation versus $\mathrm{Vdd}$ (the $1.2 \mathrm{~V}$ speed of $200 \mathrm{MHz}$ is a simulation result, because the testing board did not support high-speed testing). The maximum measured operating speed at $400 \mathrm{mV}$ is $475 \mathrm{KHz}$ in active energy per read [14].

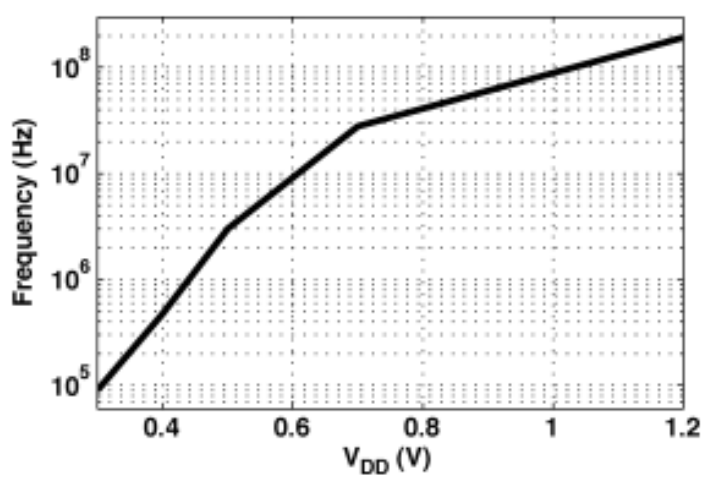

Fig.7. Frequency versus $V_{D D}[14]$

Voltage scaling is an effective strategy for minimizing the power consumption of SRAMs. Further, as SRAMs continue to occupy a dominating portion of the total area and power in modern ICs, the resulting total power saving is significant. Unfortunately, however, conventional SRAMs, based on the $6 \mathrm{~T}$ bit-cell, fail to operate at voltages below approximately at $700 \mathrm{mV}$, both because of the reduced signal levels and of increased variation. In sub-Vt, in particular, threshold voltage variation has an exponential effect on the drive current, resulting in increased cell instability and a severely degraded read-current. To address these limitations, an $8 \mathrm{~T}$ bit-cell is incorporated into a $65 \mathrm{~nm}$ and $256 \mathrm{~kb}$ SRAM, and it achieves full read and write functionality deep into the sub-Vt regime at $350 \mathrm{mV}$. At this voltage, the total leakage power is $2.2 \mu \mathrm{W}$, and the operating speed is $25 \mathrm{KHz}$ as shown in the Fig.8 and Fig.9. The significantly reduced speed is expected in sub-Vt and is acceptable for low throughput, energy-constrained applications. At $350 \mathrm{mV}$, the leakage power represents almost $85 \%$ of the total power consumption, so, the leakage reduction is a critical consideration. Additionally, the tradeoff between the size of a sense-amplifier and its statistical offset is emerging as a primary limitation to SRAM scaling in advanced technologies. In this design, enabling sub-Vt write requires the use of circuit assists that result in a layout where sense-amplifier multiplexing between the adjacent columns is impractical. Accordingly, the sense-amp scaling limitation is stressed, necessitating a different approach for managing the offset-area tradeoff. The concept of senseamp redundancy is introduced, and it is demonstrated that, for a given area constraint, errors in the sensing network due to offsets can be reduced by over an order of magnitude. In this design, a factor of five improvements is expected with the implemented scheme, which incorporates a simple startup control loop.

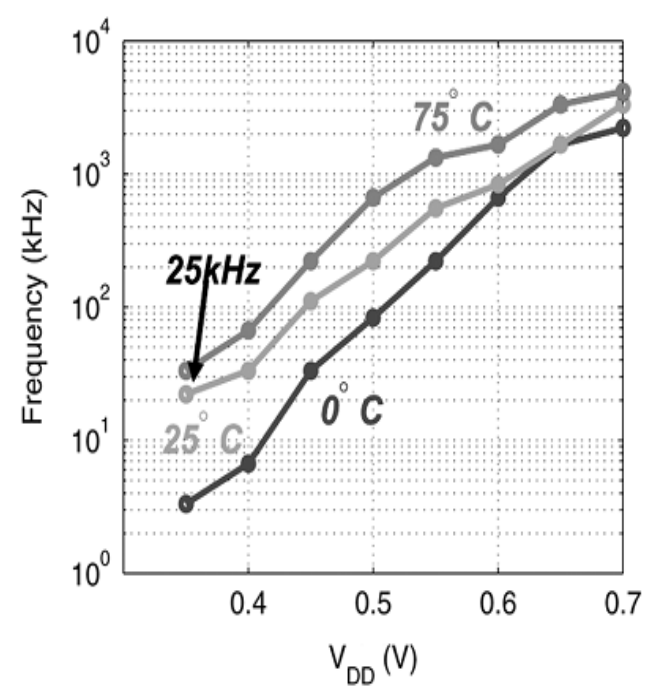

Fig.8. Frequency versus $V_{D D}$ Curve [17]

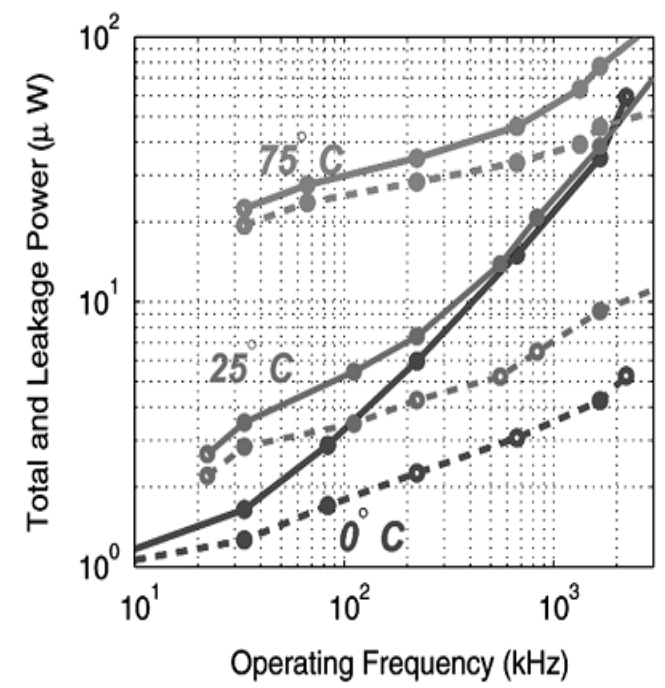

Fig.9. Leakage power vs. operating frequency curve [14]

TABLE-1. Performance ReVIEW of CONVEntional SRAm CELls at VARIOUS TECHNOLOGIES

\begin{tabular}{|c|c|c|c|c|c|c|}
\hline 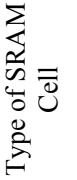 & 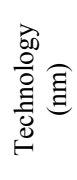 & 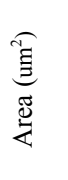 & 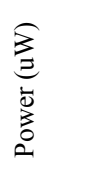 & 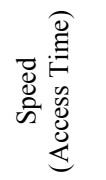 & 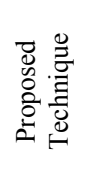 & 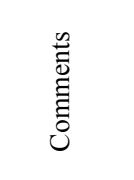 \\
\hline 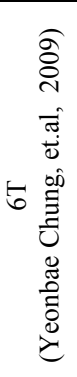 & 180 & $\begin{array}{l}\text { Area } \\
\text { Over } \\
\text {-head } \\
\text { by } \\
4.5 \%\end{array}$ & $\begin{array}{l}\text { Power } \\
\text { increased } \\
\text { by } 14.6 \% \\
\text { and } \\
\text { Standby } \\
\text { Current } \\
\text { by1.2uA }\end{array}$ & $\begin{array}{l}\text { Improved } \\
\text { Chip } \\
\text { Cycle } \\
\text { Time } \\
\text { Reduce } \\
\text { by } 26 \%\end{array}$ & $\begin{array}{l}\text { Dual } \\
\text { Boosti- } \\
\text { ng of } \\
\text { WL, } \\
\text { Cell } \\
\text { W/L is } \\
1\end{array}$ & $\begin{array}{l}\text { At Low- } \\
\text { Voltage } \\
(0.8 \mathrm{~V}) \text {, the } \\
\text { Read and } \\
\text { Write } \\
\text { Margins } \\
\text { Increased by } \\
76 \% \text { and } \\
54 \% \text {, } \\
\text { respectively. }\end{array}$ \\
\hline
\end{tabular}




\begin{tabular}{|c|c|c|c|c|c|c|}
\hline 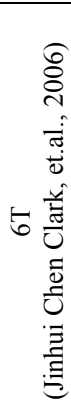 & 130 & - & $\begin{array}{l}\text { Improved } \\
\text { 1. Read } \\
\text { Operation } \\
\text { at } 190 \mathrm{mV} \\
\text { 2.Write } \\
\text { Operation } \\
\text { at } 216 \mathrm{mV} \\
\text { 3. Power } \\
\text { Consumpti } \\
\text {-on } \\
1.197 \mu \mathrm{W}\end{array}$ & $\begin{array}{l}\text { Power } \\
\text { Compro- } \\
\text { mised } \\
\text { at the } \\
\text { Sub- } \\
\text { threshold } \\
\text { Voltage }\end{array}$ & $\begin{array}{l}\text { Gate } \\
\text { Feedba } \\
\text {-ck } \\
\text { Cell }\end{array}$ & $\begin{array}{l}\text { At Sub- } \\
\text { Threshold } \\
\text { Voltage } \\
\text { Stability } \\
\text { Compromise- } \\
\text { d as the Read } \\
\text { Current raise } \\
\text { the Logic } \\
\text { Low Voltage } \\
\text { Level }\end{array}$ \\
\hline 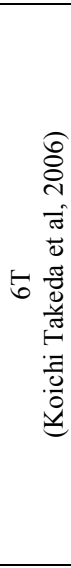 & 90 & - & $\begin{array}{l}\text { Improved } \\
\text { Supply } \\
\text { Voltage } \\
0.5 \mathrm{~V} \text { and } \\
\text { Vdd(min) } \\
\text { is } 44 \mathrm{mV}\end{array}$ & $\begin{array}{l}\text { Improved } \\
\text { Speed }\end{array}$ & $\begin{array}{l}\text { 1.Incre } \\
\text {-ased } \\
\text { Vth of } \\
\text { the } \\
\text { nMOS } \\
\text { Transis } \\
\text {-tors } \\
\text { 2.Drop } \\
\text {-ping } \\
\text { the } \\
\text { WL } \\
\text { Voltag } \\
\text {-e } \\
\text { level } \\
\text { from } \\
\text { Vdd at } \\
\text { the } \\
\text { Read } \\
\text { Operat } \\
\text {-ion. }\end{array}$ & $\begin{array}{l}\text { Write } \\
\text { Operation at } \\
\text { Lower } \\
\text { Voltage can't } \\
\text { performed } \\
\text { and the Read } \\
\text { Operation at } \\
\text { the Low-Vdd } \\
\text { levels results } \\
\text { in Low } \\
\text { Storage } \\
\text { Destruction } \\
\text { due to the } \\
\text { pMOS Cells' } \\
\text { Leakage } \\
\text { Current }\end{array}$ \\
\hline 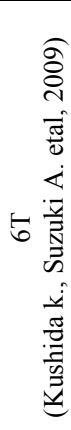 & 65 & $\begin{array}{l}\text { Area } \\
\text { Impr- } \\
\text { oved } \\
0.495 \\
\text { um }^{2}\end{array}$ & 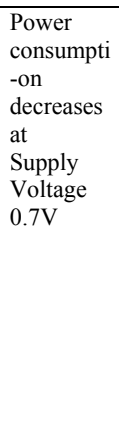 & $\begin{array}{l}\text { Depends } \\
\text { on the } \\
\text { Number } \\
\text { of Sense } \\
\text { Amplifier } \\
-\mathrm{s}\end{array}$ & $\begin{array}{l}\text { Self- } \\
\text { Write- } \\
\text { Back } \\
\text { Sense } \\
\text { Amplif } \\
\text {-ier } \\
\text { and } \\
\text { Cascad } \\
\text {-e Bit- } \\
\text { line } \\
\text { Schem } \\
\text {-e }\end{array}$ & $\begin{array}{l}\text { Preferred for } \\
\text { Low SRAM } \\
\text { Macros and } \\
\text { Low Voltage } \\
\text { Operations }\end{array}$ \\
\hline 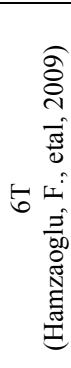 & 45 & $\begin{array}{l}\text { Impr- } \\
\text { oved } \\
\text { for } \\
\text { High } \\
\text { Dens } \\
\text {-ity }\end{array}$ & $\begin{array}{l}\text { Power } \\
\text { conumptio } \\
-n \text { is } \\
\text { reduced }\end{array}$ & $\begin{array}{l}\text { Speed } \\
\text { Improved }\end{array}$ & $\begin{array}{l}\text { 1.High } \\
-\mathrm{K} \\
\text { Metal } \\
\text { Gate } \\
\text { 2.FBB } \\
\text { for } \\
\text { pMOS }\end{array}$ & $\begin{array}{l}\text { Feature Size } \\
\text { appreciates } \\
\text { High Density } \\
\text { Circuits. } \\
\text { Improved } \\
\text { Dynamic } \\
\text { Stability and } \\
\text { Leakage } \\
\text { Reduction. }\end{array}$ \\
\hline
\end{tabular}

\section{CONCLUSION}

As the battery operated devices are in great demand and to increase their reliability, the life time of battery is a prime concerned but this is done at the cost of speed. But in high speed circuits where speed is the major concern like wireless communications these low-leakage SRAM fails. For low-leakage and high-speed circuits concern should be on both the factors speed and power. This paper tries to incorporate the issue of speed which remains uncovered in SRAM designs. In a Conventional 6T-SRAM Cell, as we consider the devices of Small-Feature Sizes $(180 \mathrm{~nm}$ to $45 \mathrm{~nm}$ ), area improves which directly reflects the highdensity circuits, a good feature for the multimedia systems where more memory is required. But on the other side, it brings several other issues related to the device performance. For $180 \mathrm{~nm}$ technology node with $\mathrm{W} / \mathrm{L}$ as 1 and DualBoosting of wordline, speed is trying to be achieved at the cost of area, and power where at the $130 \mathrm{~nm}$ feature size with gate feedback cell, power is improved speed and stability are compromised. The SRAM Cell at $90 \mathrm{~nm}$ node with increased Vth of the NMOS transistors have improved the power (Vdd $0.5 \mathrm{~V}$ and $\mathrm{Vdd}(\mathrm{min})$ is $44 \mathrm{mV}$ ) and speed, simultaneously. The Self-Write-Back Sense Amplifier and Cascade Bit-line Scheme at $65 \mathrm{~nm}$ technology (Cell size $0.495 \mathrm{um}^{2}$ ) is best suited for Small Size SRAM and LowVoltage Operation. The access speed depends on the number of Sense Amplifiers. The High-K Metal Gate and FBB for pMOS at $45 \mathrm{~nm}$ feature size allow a high density memory circuit along with the improvement in the power and speed performances with an extra care for the data stability.

\section{ACKNOWLEDGEMNET}

The authors are grateful to their respective organizations for the continuous support and encouragement.

\section{REFERENCES}

[1] A. Agarawal, H. Li, and K. Roy, "DRG-cache: A data retention gated-ground cache for low power," in Proc. Design Automation Conf., 2002,pp. 473-478.

[2] H. Yamauchi et al., "A $0.8 \mathrm{~V} / 100 \mathrm{MHz} / \mathrm{sub}-5 \mathrm{~mW}$ operated mega-bit SRAM cell architecture with charge- recycle offset-source driving (OSD) scheme," in Proc. Symp. VLSI Circuits, 1996, pp. 126-127.

[3] A. J. Bhavnagarwala, A. Kapoor, and J. D.Meindl, "Dynamicthreshold CMOS SRAM's for fast, portable applications," in Proc. ASIC/SOC Conf., 2000, pp. 359-363.

[4] K. Osada et al., "16.7 fA/cell tunnel-leakage-suppressed $16 \mathrm{Mb}$ SRAM for handling cosmic-ray-induced multi-errors," in Proc. Int. Solid-State Circuits Conf., 2003, pp. 302-303.

[5] H. Kawaguchi, Y. Itaka, and T. Sakurai, "Dynamic leakage cutoff scheme for low-voltage SRAM's," in Proc. Symp. VLSI Circuits, 1998,pp. 140-141.

[6] C. H. Kim and K. Roy, "Dynamic Vt SRAM: A leakage tolerant cache memory for low voltage microprocessors," in Proc. Int. Symp. Low Power Electronics and Design, 2002, pp. 251-254.

[7] K. Flautner et al.(2002), "Drowsy caches: Simple techniques for reducing leakage power," in Proc. Int. Symp. Computer Architecture, 2002, pp. 148-157.

[8] Chris Hyung-il kim, Jae-Joon Kim, Saibal Mukhopadhyay, kaushik roy(2005), "A forward body biased low leakage SRAM cache: Device Circuit Architecture Consideration.'IEEE transactions on VLSI systems, vol.13, Issue March 2005, pp.-349-357

[9] Kevin Zhang etal.(2005), "SRAM design on 65nm CMOS technology with dynamic sleep transistor for leakage reduction", Solid-State Circuits, IEEE Journal , vol. 40,April 2005, Issue: 1, pp. 895-901.

[10] Kaushik Roy et al.(2003), "Leakage Current Mechanisms and Leakage Reduction Techniques in Deep-Submicrometer CMOS Circuits", Proceedings of the IEEE,vol.. 91, Issue. 2, February 2003,pp-305-327.

[11] Jinhui Chen Clark, L.T. Tai-Hua Chen, "An Ultra-Low-Power Memory with a Subthreshold Power Supply Voltage", Solid-State Circuits, IEEE Journal, vol.41, Oct 2006, Issue: 10, pp- 2344-2353.

[12] Hiroki Noguchi et al., "Which is the best dual port SRAM in $45 \mathrm{~nm}$ process technology?8T,10T single end and 10T differential" Renesas Technology corporation, 2008.

[13] Naveen verma, Anantha P. Chandrakasan, "A reconfigurable $65 \mathrm{~nm}$ SRAM achieving voltage scalability from $0.25 \mathrm{~V}-1.2 \mathrm{~V}$ \& performance scalability from $20 \mathrm{Khz}-200 \mathrm{Mhz}, 34$ th European SolidState Circuits Conference, 2008. ESSCIRC 2008, pp-282-285.

[14] Benton H. Calhoun Anantha P. Chandrakasan, "A 256-kb 65-nm Sub-threshold SRAM Design for Ultra-Low-Voltage Operation", Solid-State Circuits, IEEE Journal vol. 42, March 2007, Issue 3, pp.680-688.

[15] Muhammad Khellah etal.," A 256-Kb Dual-VCC SRAM Building Block in 65-nm CMOS Process With Actively Clamped Sleep 
Transistor, Solid-State Circuits, IEEE Journal vol. 42, January 2007, No.1 , pp.233-247.

[16] Yeonbae Chung ,Seung-Ho Song, "Implementation of low-voltage static RAM with enhanced data stability and circuit speed", Microelectronics Journal vol. 40, Issue 6, June 2009, pp. 944-951.

[17] Jinhui Chen Clark, L.T. Tai-Hua Chen, "An Ultra-Low-Power Memory with a Subthreshold Power Supply Voltage", Solid-State Circuits, IEEE Journal, vol.41, Oct 2006, Issue: 10, pp- 2344-2353.

[18] Koichi Takeda et al, "A Read Static Noise Margin Free SRAM cell for Low Vdd and High Speed Applications",Solid-State Circuits, IEEE Journal vol. 41, Jan.2006, Issue 1, pp.113-121.

[19] Kushida k.,Suzuki A.etal, “A 0.7 V Single-Supply SRAM With 0.495 $\mu \mathrm{m}^{2}$ in $65 \mathrm{~nm}$ Technology Utilizing Self-Write-BackSense Amplifier and Cascaded Bit Line Scheme, , Solid-State Circuits, IEEE Journal ,vol. 44 , no. 4, April.2009, pp.1192-1198.

[20] Hamzaoglu, F.; Zhang, K.; Yih Wang; Ahn, H.J.; Bhattacharya, U.; Zhanping Chen; Yong-Gee Ng; Pavlov, A.; Smits, K.; Bohr, M , "A $3.8 \mathrm{GHz} 153 \mathrm{Mb}$ SRAM Design With Dynamic Stability Enhancement and Leakage Reduction in $45 \mathrm{~nm}$ High-k Metal Gate CMOS Technology”, Solid-State Circuits, IEEE Journal ,vol. 44 , no. 1, 2009, pp. $148-154$.

[21] Byung Do Yang, "A low power SRAM using Bit line charge Recycling for read \& write operations". Solid-State Circuits, IEEE Journal, vol. 45, no. 10, 2010, pp.2173-2183.

Neeraj Kr. Shukla (IEEE, IAENG, IE), Asst. Professor in the Department of Electrical, Electronics and Communication Engineering, ITM University, Gurgaon, Haryana is a Research Scholar in UK Technical University, Dehradun (Uttarakhand). He has received his M.Tech. (Electronics Engineering) and B.Tech (Electronics \& Telecommunication Engineering) Degrees from the J.K. Institute of Applied Physics \& Technology, University of Allahabad, Allahabad (Uttar Pradesh) India in the year of 1998 and 2000, respectively. His main research interests are in Low-Power Digital VLSI Design and its Multimedia Applications, Open Source EDA, VerilogHDL, and RTL Design.

Shilpi Birla (IAENG) Astt. Professor in the Department of Electronics \& Communication Engineering, Sir Padampat Singhania University, Udaipur is a Research Scholar in Uttarakhand Technical Unversity, Dehradun
(Uttarakhand). She has received her M.Tech. (VLSI Design) and B.E. (Electronics \& Communication Engineering) Degrees from the University of Rajasthan, Jaipur (Rajasthan) India and MITS University, Laxmangarh, (Rajasthan) India, respectively. Her main research interests are in LowPower VLSI Design and its Multimedia Applications, RF SiP, and LowPower CMOS Circuit Design.

R.K. Singh (IAENG, ACEEE, IE, ISTE), Professor in the Department of Electronics \& Communication Engineering, Kumaon Engineering College, Dwarahat, Almora (UK) is being honored with the Ph.D. in Electronics Engineering in the Year 2003 from the University of Allahabad, Allahabad (Uttar Pradesh), India. He has received his M.E. (Electronics \& Control Engineering) in 1992 from BITS, Pilani and B.E. (Electronics \& Communication Engineering) in 1990 from Marathawada University. He authored four books in the field of VLSI Design, Basic Electronics, and Opto-Electronics. He shared various responsibilities as, the Principle, Kumaon Engineering College, Dwarahat in the year 2003-04, Director (O), Directorate of Technical Education, Uttaranchal in the year 2005, and Joint Director, State Project Facilitation Unit, Dehradun for the World Bank TEQIP Project. He is also the recipient of several awards, Rastriya Samman Puruskar, Jewel of India Award, Rastriya Ekta Award, Life Time Achievement Award, and Arch of Excellence Award. His current areas of interest are VLSI Design, Opto-Electronics.

Manisha Pattanaik (WSEAS, IE, ISTE) is being honored Ph.D. from IIT Kharagpur in the field of VLSI Design from the Department of Electronics and Electrical Communication Engineering in the year of 2004. Currently she is an Assistant Professor (VLSI Group) at ABV-India Institute of Information Technology \& Management (ABV-IIITM), Gwalior, Madhya Pradesh, India. She has been awarded various scholarships, e.g., National Scholarships, Merit Scholarships and MHRD Fellowships. She shared the responsibility in the capacity of referee for IEEE International Conferences on VLSI Design for two consecutive years, 2003-04. Her areas of interest are Leakage Power Reduction of Nano-Scale CMOS Circuits, Characterization of Logic Circuit Techniques for Low-Power/Low-Voltage and High performance analog and digital VLSI applications and CAD of VLSI Design. 